\title{
Modeling Domestic Lighting Energy Consumption in Romania and Integrating Consumers' Behavior
}

\author{
Ion Smeureanu $^{a}$, Roman Kanala $^{b}$, Adriana Reveiu $^{\mathrm{a}, *}$, Marian Dardala $^{a}$ \\ ${ }^{a}$ Bucharest University of Economic Studies, 6 Piata Romana, 1st district, Bucharest, Romania,010374 \\ ${ }^{b}$ University of Geneva, Institute of Environmental Sciences, Site de Batelle, Bat. D / 7 route de Drize, Carouge, Geneva, \\ Switzerland, $\mathrm{CH}-1227$
}

\begin{abstract}
Sustainable energy consumption is a research area of a large interest in the last years. New energy-efficient lighting technologies exist, and can significantly reduce household electricity consumption, but their adoption has been slow. A considerable number of international studies show that sustainable development scenarios will be realistic if they involve the human behavior.

The paper provides a solution to integrate consumer behavior with techno-economic energy issues, inside a complex energy model. This approach aims to reduce the systematic error on the demand side of the energy model that stems from the hypotheses of perfect information and of perfect economic rationality. These hypotheses are common to all optimization models based on the concept of economic equilibria. The TIMES energy modeling software tool has been used to integrate the techno-economic energy specific data and consumer behavior. Consumer behavior in energy consumption is described using specific attributes of energy technologies as virtual technologies. Technical coefficients of virtual technologies come from a sociological survey about Romanians' behavior in energy consumption. This approach, known as "Social MARKAL", allows the analyst to evaluate the possible contribution of information campaigns in changing lighting consumers' behavior and effect of technology switch. The model is developed for the period 2010-2026, and is implemented by using TIMES/VEDA software platform. The implementation presented this paper focuses on the household lighting technologies but the approach can be extended to other demand sectors as well.
\end{abstract}

Keywords: TIMES/VEDA model for Romania; behavior change; energy savings; consumer behavior modeling

\section{Introduction}

Residential lighting technologies endorsed important increases in energy efficiency in recent years. Compact fluorescent bulbs and light emitting diodes require about $80 \%$ and $85 \%$ less electricity compared to incandescent bulbs and last from 6 to 26 times longer, respectively [1],[2].

Thus, widespread adoption of new technologies has the potential to significantly reduce household electricity consumption, which accounts for about $26.7 \%$ of electricity consumption in the EU-27 [3], and about $23.1 \%$ in Romania.

${ }^{*}$ Corresponding author. Tel.: +4-021-3191900

Fax: +4-021-3112066; E-mail: reveiua@ase.ro

(C) 2015 International Association for Sharing Knowledge and Sustainability

DOI: $10.5383 /$ ijtee.10.02.003
The main factors that obstructed the diffusion of energyefficient lighting bulbs are considered to be: bulbs size and shape, perceived lower quality of light, warm-up period before achieving full brightness, and higher initial purchase costs [4]. Many final consumers are not aware of the advantages of new technologies and in that case, information campaigns may influence their purchase choices and improve the rate of technology switch. Information campaigns may also act on consumer behavior when it comes to energy use. Many European countries have implemented measures to speed up the transition process to new technologies, like imposing administrative ban on import and domestic sales of incandescent light bulbs, or supporting awareness campaigns 
about new technologies. The implications of proposed scenarios can be evaluated using optimization models that integrate both techno-economic approach and social behavior of final consumers.

Optimization models are useful to find the optimal investment path minimizing the global cost of the energy system: which technology, how much and when to invest in. [5]

Classical optimization models that include only tangible technologies have a major disadvantage, namely suppose consumers with perfect economic rationality and consumers with updated and full economic and technological information. Typically, the behavior of final consumers of energy is not rational because they are not in possession of all necessary information and because their personal preferences do not necessarily correspond to the economic criterion of minimal cost. For these reasons, we are considering not only the "classical" tangible technologies in competition, but also the consumer behavior to be included in the optimization model. Describing consumer behavior like a technology has the advantage to be able to keep all the model formalism intact and end up with a usual linear model [6].

In order to obtain the technical coefficients for virtual technologies, a sociological survey, representative for Romania's population has been conducted. Some rational but non-economic factors which determine the consumption decision for lighting were identified, along with some irrational factors that make people acquire and use old incandescent bulbs or overconsume light.

The results gathered from sociological survey have been integrated in TIMES/VEDA energy model developed for Romania.

The TIMES model is using information about the efficiency of technologies. In order to comply with this requirement, we determine the equivalent of efficiency of virtual technologies by measuring the consumers' information, perception, and behavior.

The rest of paper is structured as following: the next section includes a brief literature review about techno-economic energy models and about the consumers' behavior in energy consumption. Section 3 includes a brief description of TIMES model implemented for Romania, and the section 4 proposes the solution implemented for Romania, to integrate behavior parameters into TIMES/VEDA model. The last section includes main findings and future works.

\section{Literature Review about Techno-Economic Energy Models and Consumer Behavior}

Sustainable energy consumption is a research field of a large interest in the last years. New energy efficient lighting technologies exist, which can significantly reduce household electricity consumption, but their adoption has been slow. Thus, sustainable development scenarios may become more realistic if, in addition to technology progress, they include the human behavior.

Elaborating techno-economic energy models is the first step toward identifying and understanding the key issues, drivers and barriers to development sustainable solutions for energy consumption.

A techno-economic energy model is a mathematical representation of an energy system, describing its configuration, technologic and economic characteristics of its components [7]. Long term techno-economic energy models can be used to determine the optimal configuration of an energy system in terms of efficiency, costs, environmental impacts, and to predict future behavior of a system. A variety of techno-economic energy models has been developed, like: MARKAL (MARket ALlocation), TIMES (The Integrated MARKAL-EFOM System), and OSeMOSYS (Open Source Energy Modeling System), each serving particular purposes.

MARKAL model framework has been developed by the ETSAP (Energy Technology Systems Analysis Program) under the auspices of the IEA (International Energy Agency). It has been widely applied for energy system modeling on global to community level, to facilitate investigation of possible energy futures.

TIMES has been developed by IEA-ETSAP as a successor of MARKAL and includes several features adopted from EFOM model, like flexible time step, a better description of technologies as well as other enhanced features.

OSeMOSYS is an open source, compact modeling framework, developed by some cooperating organizations including: SEI (Stockholm Environment Institute), the IAEA (International Atomic Energy Agency), the UK Energy Research Center, and the KTH (Royal Technical University of Sweden).

Since 2005 , there has been an emerging trend to apply social and behavior science to energy research [8]. Often, the effectiveness of energy is studied without examining the underlying behavioral determinants of energy use and energy savings. Only few studies examine both the effectiveness of an intervention as well as changes in determinants of energy use, and fewer provided detailed impact evaluation [8].

Sustainable energy consumption supposes to reduce the energy consumption to a sustainable level. On the demand side, this goal can be achieved by improving the energy efficiency by investing in better technologies, or by energy conservation which means changing the behavioral habits when it comes to energy consumption. Thus the two types of behavior that people can adopt to save energy are investment behavior and consumption behavior that occur at different time scales. Technology purchase occurs occasionally, and comprises the acquisition of new appliances and sometimes the adoption of new technologies. Habitual behavior is a routine everyday behavior that individuals repeat automatically without conscientiously weighting the pros and cons, such as switching off the lights when leaving a room [8]. The two types of behavior, technology switch (information-triggered investment into a better technology) and energy savings (informationtriggered behavioral change toward less energy use) are covering all the cases of behavioral change [9].

\section{TIMES/VEDA Model Implementation for}

\section{Romania}

TIMES (The Integrated MARKAL EFOM System) is a longterm optimization model developed by the Energy Technology Systems Analysis Programme, under the aegis of International Energy Agency. This tool combines a technical engineering approach and an economic approach to represent technologies, fuels, emissions and their effect on economic sectors. VEDA (Versatile Data Analyst) is the user interface that can be used with TIMES model generator. 
TIMES models establish relationships between the variables describing extraction, transportation, storage, energy conversion processes from one energy form to another, and the demand technologies towards the final consumer, according with Reference Energy System (RES). RES is a schematic representation of network form, designed to display the activities and relationships of an energy system.

TIMES models are constructed from basic entities [10]:

- Technologies (processes) are physical devices that transform commodities into other commodities. At the end of the chain there are demand technologies. They take energy as input and transform it to useful demands on the output. Technologies are characterized by parameters like: efficiency, capacity, costs and so on.

- Commodities (including fuels) are energy carriers, energy services, materials, monetary flows, and emissions; a commodity is either produced or consumed by some technology.

- Commodity flows are the links between processes and commodities. A flow is of the same nature as a commodity but is attached to a particular process, and represents one input or one output of that process.

To set up the energy model the following data sources have been used:

- Romanian Reference Energy System statistics for the base year (2010), used to calibrate the model;
- 2014 Population and Housing Census (provided by Romanian National Institute of Statistics) for data about demand drivers.

- For technologies we developed the Romanian technology database.

The goal being to introduce the social behavior of lighting consumers, we developed a very simple but robust TIMES model for Romania that consists only of the demand side and where the energy supply to demand devices is modeled in form of virtual imports. These are equal to domestic energy production plus the real transboundary energy imports.

From the complete Romania's TIMES model, we detail in this section only the household energy consumption sector.

The demand side of household energy consumption uses various energy carriers and services, by using Reference Energy System of Romania as the basis, as presented in figure 1.

The modeled processes are: lighting (with various fuels: kerosene; incandescent, fluorescent, LED: electricity), space cooling (electricity), space heating (fuels: natural gas, biomass/wood, oil products, coal, solar energy), combined space heating - hot water SH-HW, hot water (fuels: natural gas, biomass/wood, oil products, coal, solar), refrigeration (electricity), washing machine (electricity), dish washing (electricity), cloth dryers (electricity), others (electricity).

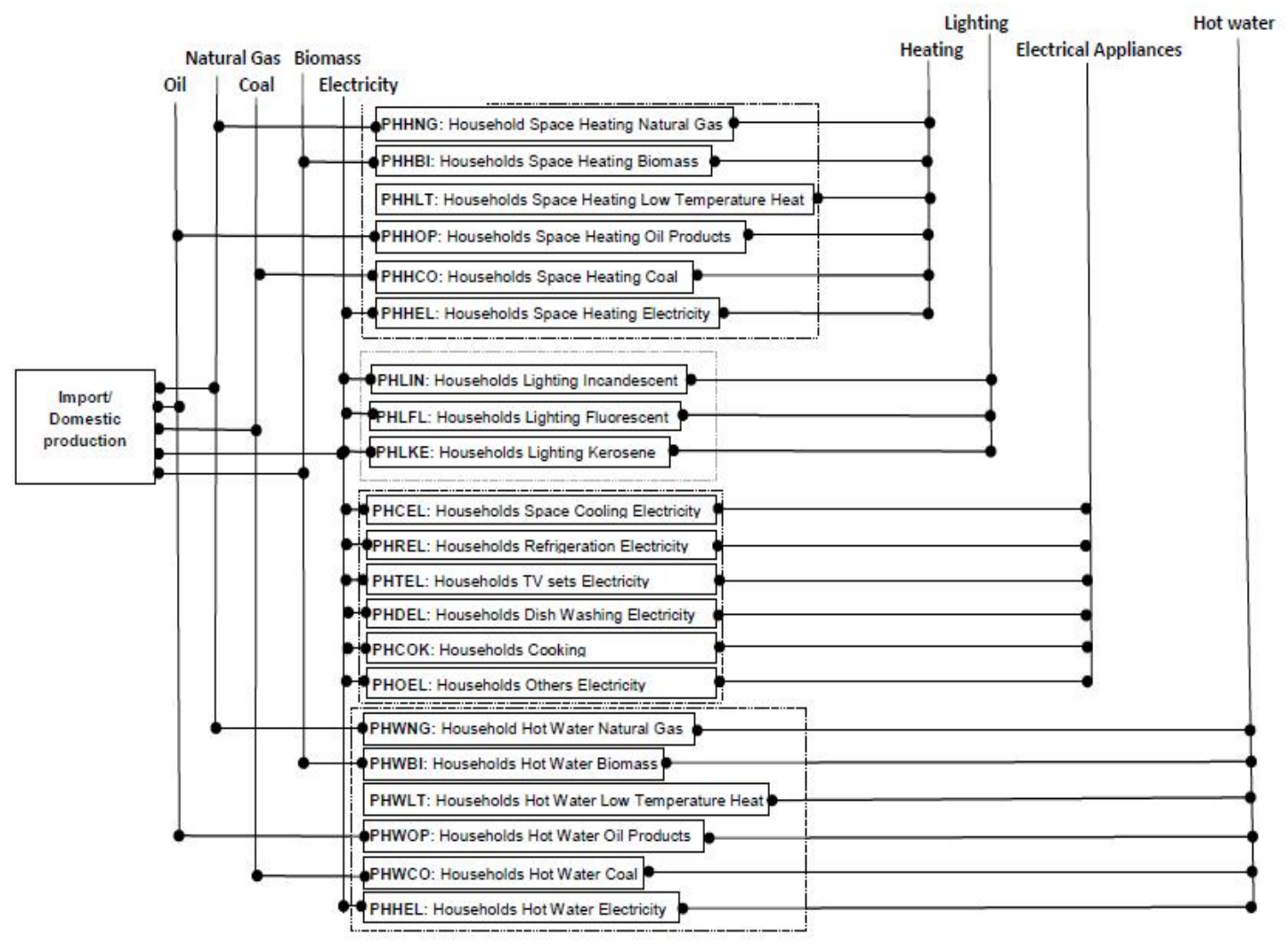

Fig. 1. TIMES model of Romania. The households sector 
The formulation of the model was done by using TIMES model generator that gives the resulting model in GAMS (General Algebraic Modeling System). GAMS is a computer language specifically created to facilitate the development of algebraic models.

Construction, handling, and maintenance of large scale models are difficult without a performing user-friendly interface. VEDA (VErsatile Data Analyst) interface offers a user customized tool for handling files, databases and results from large - scale mathematical and economic models. The proposed implementation makes use of both VEDA components:

- VEDA-FrontEnd which supports TIMES models, for input data handling, being used in several multi-region applications in USA and Europe;

- VEDA-BackEnd which is a very versatile and powerful interface to look at a variety of results from the model, in different presentation formats.

\section{Modeling Consumer Behavior and Integrating into the Techno-Economic Energy Model}

Because the classical TIMES model is not designed to model the consumer behavior, virtual technologies have been introduced. Virtual technologies are used to model both the information-triggered energy savings and the informationtriggered technology switch that complete the competition between demand technologies. Virtual technologies are processes that take electricity as fuel and produce nonenergetic commodities as output, like awareness. In order to prevent unlimited use of behavioral virtual technologies, these cannot be free but are required to have an investment cost that corresponds to the cost of the information campaign. Information campaign is the enabler and information-triggered downstream behavioral change is then free. That way, instead of using usual bounds on demand side management measures, behavioral change is entering in competition with tangible technologies, all that within the same optimization modeling platform [9], [11].

The consumers' opinions could be influenced in various ways: from energy labels through marketing campaigns to legal measures and restrictions imposed by governmental institutions.

To model the consumers' behavior we used data from sociological survey, about consumers favorable for technology switch and about consumers favorable for rational energy use.

The survey was representative for the adult population of Romania and has been conducted on a sample of 400 residents of urban and rural localities, from all regions of Romania between September and November 2013. The survey used a representative sampling technique - the sample used a random geographic sample across Romania. The target of this survey is the adult population Romania, and face-to-face interviewing method has been applied. The aim of the survey questionnaire is to assess the potential contribution of behavioral change in end-use lighting energy consumption pattern. The sample's representativeness is very good: proportion of men $47 \%$, age average 45.42 with standard deviation 17.17. The house ownership was $88 \%$ in the survey while Eurostat 2011 says the ownership rate in Romania in 2007 was $96 \%$, overall the highest value in the EU, followed by Lithuania and Slovakia (89\%), Hungary (87\%) and Latvia (84\%). For comparison, the ownership rate in Switzerland is the lowest one in Europe with just $37 \%$. The three top features of a bulb were the same in Romania as in Switzerland: light intensity, cost and lifetime. Compared to the Western Europe, Romanians have a higher discount rate and prefer the present over the future, which is a typical survival behavior in an undercapitalized society.

Energy use modes are addressed in the sociological survey through the reasons for turning light on when entering in a room. More than half of the respondents $(50.6 \%)$ indicate a practical reason for turning on light: the need to see the entire room. The need for comfort is indicated by $40.5 \%$ of the respondents. Interestingly, habitus is the reason for $33.4 \%$ of the respondents, $17.7 \%$ of respondents turn on light for security, $12.8 \%$ because of the problems of vision, $6.1 \%$ because of their fear of obscurity, and $4.4 \%$ because of the need to illuminate all the rooms in their apartment. The level of equipment of households by low-consumption bulbs Romania is addressed through the question: "During the two last years, how many incandescent bulbs (the classical ones) did you replace by low-consumption bulbs?" As indicated in figure 2, $23.1 \%$ of the respondents already own only low consumption bulbs in their residence; for $8.4 \%$ of respondents $3 / 4$ of existing bulbs are low-consumption bulbs; for $15.5 \%$ of respondents around half of existing bulbs are low-consumption bulbs; for $26.5 \%$ of respondents around a quarter of existing bulbs are low-consumption bulbs; $18.2 \%$ of respondents do not own any economical bulb at home.

In order to find the important parameters for the model, we need to measure the proportion of people who already behave the desired way, then the proportion of people who are not behaving that way because they do not have the information about the advantages of energy savings or new technologies but once better informed, they will change their behavior, and the proportion of people who will never change because they have extra-economic reasons that dominate their personal preferences, like macular degenerescence of elderly people or sensibility to stroboscopic flicker that prevent some people from using the fluorescent bulbs, or irrational fear of obscurity which is the reason why some people keep all the lights permanently turned on.

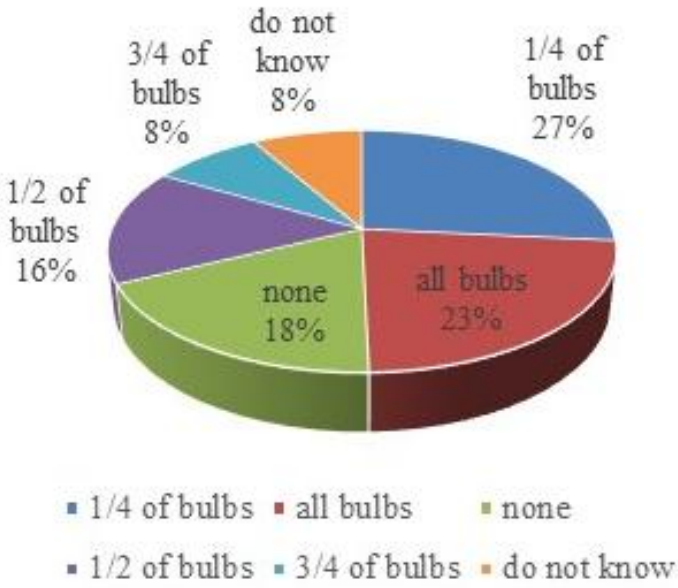

Fig. 2. Proportion of households with $0 \%, 25 \%, 50 \%, 75 \%$ and $100 \%$ of low-consumption bulbs

To model the consumer behavior we introduce two technologies: CAMP1 - Information Campaign Habitual Behavior Change, CAMP2 - Information Campaign Investment Behavior Change and four commodities: RLD1 - Existing 
Incandescent Bulbs, RLD2 - Existing Low Consumption Bulbs, RLD3 - Moderate Use of Incandescent Bulbs, and RLD4 - Switch to Low Consumption Bulbs.

The structure of consumer behavior model contains the relationships between components and is presented in figure 3.RLD1 and RLD2 represent real lighting commodities flows, receiving electricity as input and generating residential lighting. VEDA-Front End software interface is presented in figure 4. RLD3 and RLD4 represent the virtual commodities flows, corresponding to virtual technologies. They receive intangible inputs (information campaigns) and generate residential lighting. The relationship between new added virtual technology (CAMP1) and corresponding commodities (RLD1 and RLD3), displayed in VEDA-Front End software interface is presented in figure 4 .

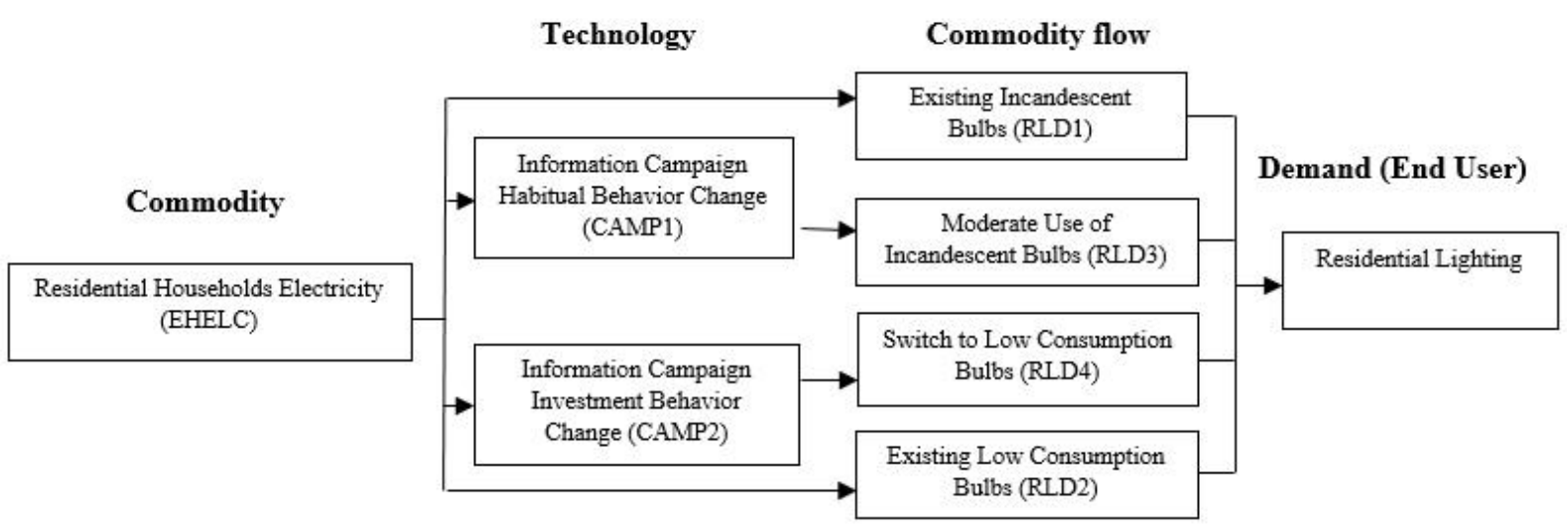

Fig. 3. Consumer Behavior Reference Model Diagram for Residential Lighting Sector

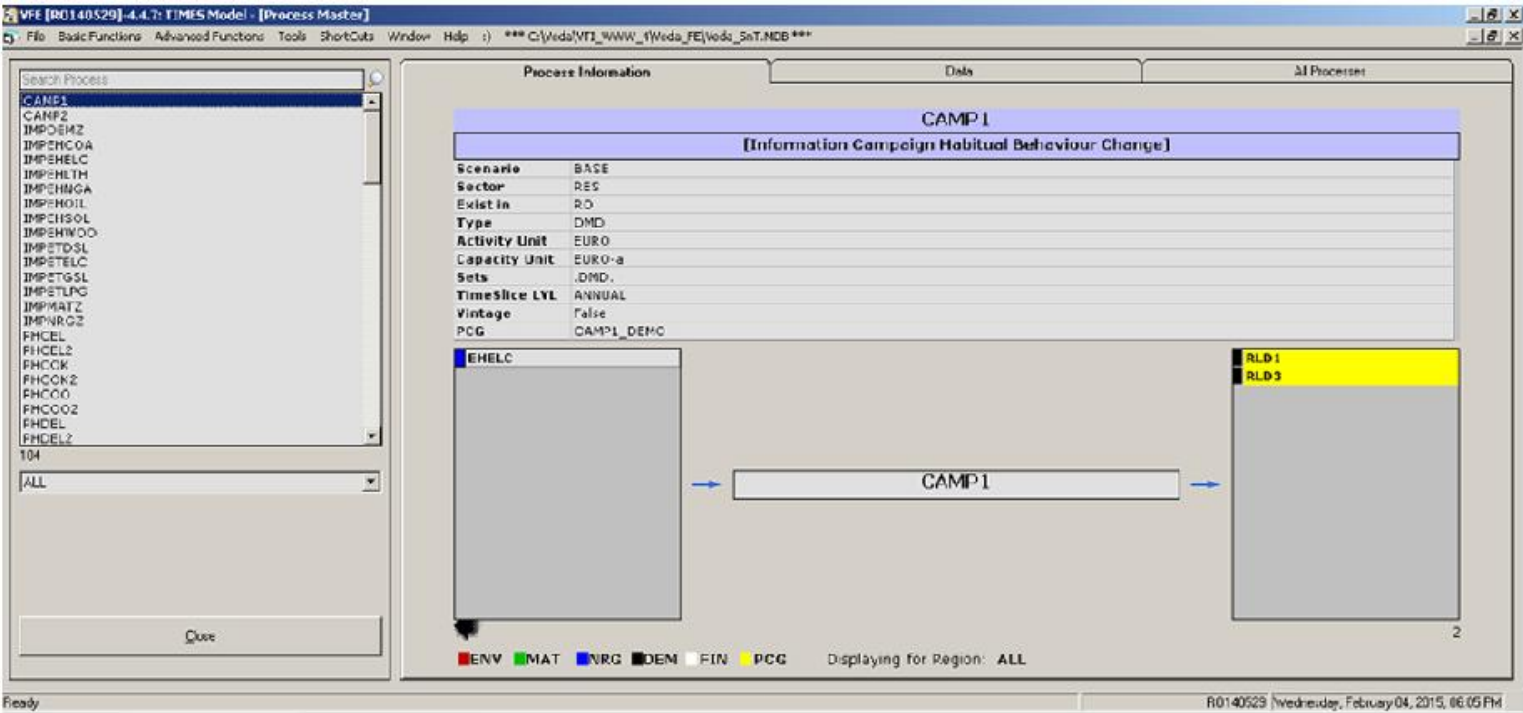

Fig.4. VEDA-Front End Interface, with new virtual technology

The results can be found by performing a sensitivity analysis, lowering the investment cost of the information campaign until the virtual process technologies representing the behavioral change become competitive with tangible technologies and enter the optimal solution. The described approach is immediately usable also for other household appliances where there is a need to separately describe the technology itself and the way consumers are using it. The biggest contribution is expected with appliances that are changing quickly and where the using mode varies across the population, like TV sets. Long-lasting appliances that are turned on all the time, like refrigerators or freezers, have a well predictable consumption over their entire lifespan. An important drawback of this approach is the need to conduct a sociological survey about the use of every type of device we wish to study.
In the figure 5, we see the result of the optimization of an unconstrained model. All the incandescent bulbs disappear immediately from the optimal solution because they are not competitive. However this is not corresponding to a real, observed behavior, which was the very reason to propose the Social MARKAL approach. In the figure 6, we see the result of the optimization with a bound introduced to represent people who claim that they will never use fluorescent bulbs because of extra-economic reasons. If the information campaign is too expensive, it does not enter into optimal solution. On the figure 7, information campaign is available starting from 2015 and since its cost is low enough, it will be immediately part of the optimal solution. 


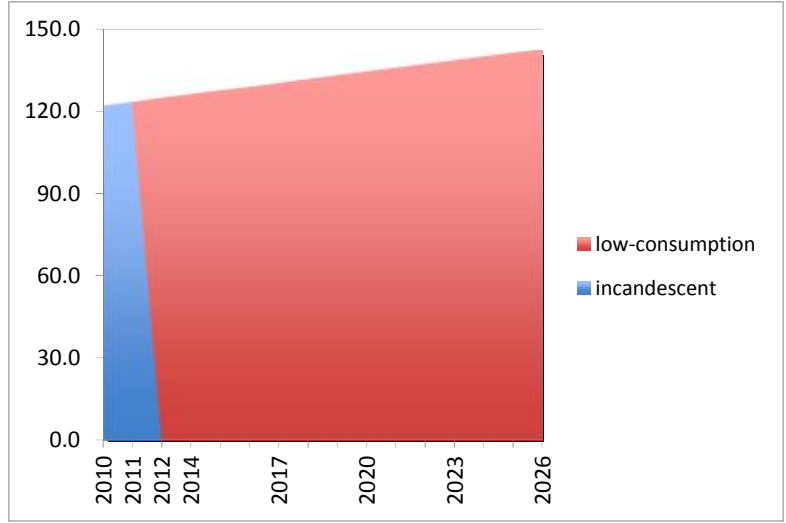

Fig. 5. Residential lighting in Gigalumens, unconstrained case incandescent bulbs are not competitive and disappear instantaneously

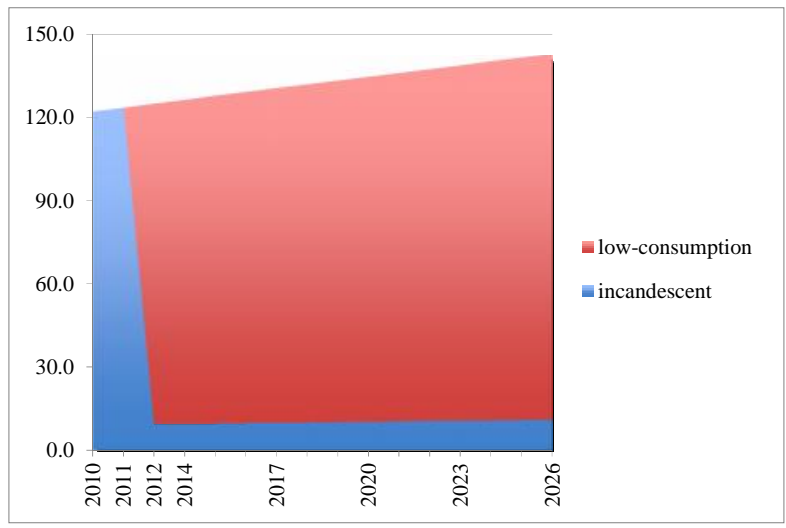

Fig. 6. Residential lighting in Gigalumens in Social TIMES Romania with no information campaign

The replacement of existing incandescent bulbs in the first years of the modeling period is decreasing the sales of bulbs as low-consumption bulbs have a much longer lifespan. There are constraints in the mode that limit the number of bulbs that can be switched off by the number of installed bulbs and other similar reasonable constraints.

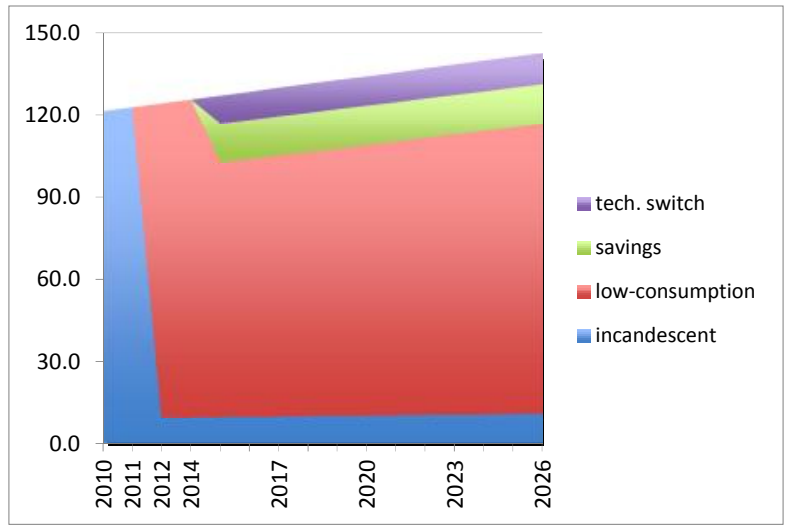

Fig. 7. Residential lighting in Gigalumens in Social TIMES Romania with information campaign active since 2015
Demand for lighting is exogenous and is supposed to be proportional to the population growth. All the three scenarios are for low growth of $+17 \%$ between 2010 and 2026 and constant electricity prices.

In the model, we are using a flexible time step. Presence of too many assumptions in the input data is making the case a fake one at this stage but it shows the possibilities of the approach.

The sector of residential heating is the next step in implementation of the same principle except that instead of tangible technologies represented by bulbs and virtual technologies representing behavioral change, we can decompose the tangible technology, residential heating, into three virtual technologies interconnected by virtual energy flows: the building envelope, its heating system and the habitants' thermal behavior [12], see figure 8 .

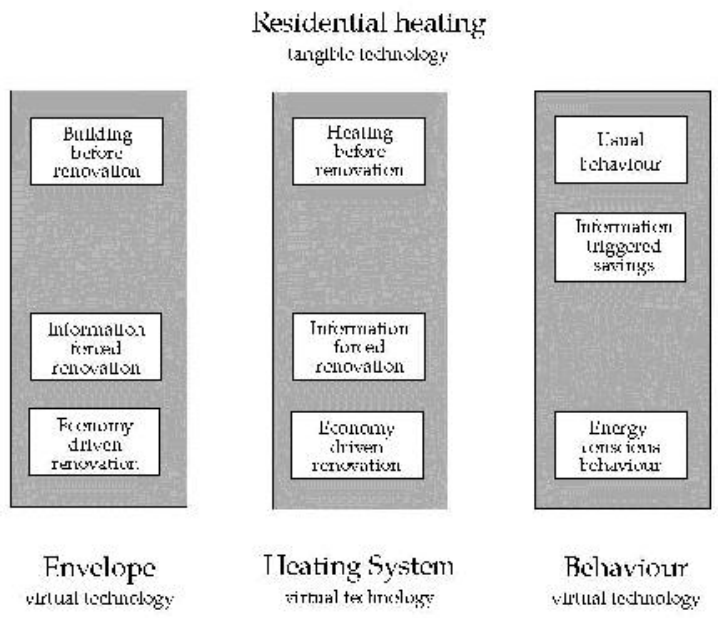

Fig. 8. Decomposition of the tangible technology Residential heating into three separate virtual technologies.

Renovations of the heating system can occur more frequently than the renovation of the envelope. A reasonable assumption is that when the building envelope is insulated, the heating system is also replaced. The inhabitants' thermal behavior is independent of the insulation and heating system efficiency.

In a similar way, in the case of passenger cars, the implementation should distinguish the choice of the car itself, the dominant purpose of the car, and the dominant driving mode.

\section{Conclusions and future works}

The paper describes a method how to integrate rational energy use and information-triggered technology switch into a technoeconomic model using a TIMES/VEDA framework in order to address the systematic error at the demand side of the energy model if the consumer behavior is neglected. Consumer behavior is described by virtual technologies with attributes similar to tangible technologies. In this approach, the possible contribution of information campaigns in changing energy consumers' behavior and the effect of technology switch is in direct competition with technology progress. The model concerns household lighting. Next steps will extend the approach to other demand sectors such as residential heating or passenger cars. 


\section{Acknowledgments}

The authors wish to thank Rocco De Miglio of e4sma Ltd., Torino, Italy, for his help with setting up the TIMES model for Romania.

This work was supported by the Swiss Enlargement Contribution in the framework of the Romanian-Swiss Research Program (Grant IZERZ0_142217, Design of a sustainable energy model by inclusion of behavioral and social parameters, 2012-2015).

\section{References}

[1] European Commission, Joint Research Centre, European LED Quality Charter, February 2011.

[2] IEA, http://mappingandbenchmarking.iea-4e.org, 2012.

[3] Bertoldi P, Hirl B, Labanca N. Energy Efficiency Status Report 2012 - electricity Consumption and Efficiency Trends in the EU-27. European Commission Joint Research Centre Institute for Energy and Transport, Ispra, Italy, 2012, DOI: 10.2788/37564.

[4] Mills B, Schleich J. Household transitions to energy efficient lighting. Energy Economics, Elsevier; 2014, no. 46, pp. 151-160, DOI: 10.1016/j.eneco.2014.08.022>

[5] Furtuna F, Reveiu A, Dardala M, Kanala R. Analysing the Spatial Concentration of Economic Activities: A Case Study of Energy Industry in Romania, Journal of Economic Computation and Economic Cybernetics Studies and Research, vol. 47, no. 4, pp. 35-52, 2013.

[6] Kanala R, Fragnière E, Moresino F, Dardala M. First Insights on Socio-MARKAL Approach Applied to
TIMES-Romania Country Model, In Proceedings of the 12th International Conference on Informatics in Economy, April 2013, pp. 585-588.

[7] Timmermana J, Vandeveldeb L, Van Eetveldea G Towards low carbon business park energy systems: Classification of techno-economic energy models, Energy, vol. 75, pp. 68-80, 2014, DOI: 10.1016/j.energy.2014.05.092.

[8] Karatasou S, Laskari M, Santamouris M. Models of behavior change and residential energy use: a review of research directions and findings for behavior-based energy efficiency, Advances in Building Energy Research, 8:2, pp. 137-147, 2014, DOI: 10.1080/17512549.2013.809275.

[9] Nguene G, Fragnière E, Kanala R, Lavigne D, Moresino F. Socio-Markal (Somarkal): First Modeling Attempts in the Nyon Residential and Commercial Sectors Taking into Account Behavioural Uncertainties, Energy for Sustainable Development, 15/1, pp. 73-83, 2011, DOI: 10.2139/ssrn.1522143.

[10] Loulou R, Remne U, Kanudia A, Lehtila A, Goldstein G. Documentation for the TIMES Model - PART I 178, 2015.

[11] Fragnière E, Kanala R, Lavigne D, Moresino F, Nguene G. Behavioral and Technological Changes Regarding Lighting Consumptions: A MARKAL Case Study, in Low Carbon Economy, Vol.1 No.1, pp. 8-17, 2010, DOI: $10.4236 /$ lce.2010.11002.

[12] Kanala R, Fragnière E, Moresino F. Extension of the Social MARKAL Concept to Residential Heating in TIMES Romania Country Model, Proceedings of the Energy for Sustainability Multidisciplinary Conference EfS 2013, Coimbra, Portugal, 8-10 September 2013. 